Ivana Martić

Nastia Degiuli

Ivan Ćatipović

http://dx.doi.org/10.21278/brod67408

ISSN 0007-215X

eISSN 1845-5859

\title{
EVALUATION OF THE ADDED RESISTANCE AND SHIP MOTIONS COUPLED WITH SLOSHING USING POTENTIAL FLOW THEORY
}

UDC 629.5:015.2:629.5.017.2:519.6

Original scientific paper

\begin{abstract}
Summary
Ship added resistance is a steady force of the second order which depends on the ship motions and wave diffraction in short waves. To predict the impact of liquid motions inside the ship hull, a flooded tank in the midship area is generated and the ship response to regular waves is calculated. Currently available mathematical models and numerical tools are used to enable new insights into the sloshing effects of a relatively large free surface of flooded water inside the ship hull. The liquid inside the tank is first considered as a solid body in order to make a distinction between the hydrostatic and the hydrodynamic effect on global ship motions. Source formulation panel method is used and wave loads acting on the ship hull are determined using the near-field formulation. Based on the potential flow theory, the influence of sloshing on the ship motions and added resistance is evaluated to get an insight into this complex hydrodynamic problem. The calculated results are compared with the available experimental data from the literature.
\end{abstract}

Key words: $\quad$ potential flow; panel method; response to waves; added resistance; drift force; quadratic transfer function (QTF); liquid motions in a tank

\section{Introduction}

When sailing in waves, a ship is exposed to different forces due to wind, waves, currents and speed of the vessel itself. It is of major importance to evaluate the ship response to waves and loads acting on the hull, particularly at sea states characterized by high waves, not only from the economic aspect but also from the environmental one [1]. The main cause of unintentional decrease in the speed of the ship is probably the added resistance in waves as it is one of the major factors that affect the ship operability [2]. Therefore, it is very important to precisely predict the ship added resistance in the actual seaway since it greatly affects the selection of the ship engine and propulsion system and has an influence on the sustainable service speed and fuel consumption [3]. Since energy saving and emission reduction are of great concern nowadays, it is also important to consider the ship response to waves when designing a ship. Due to the ship added resistance in waves, the power and the fuel 
consumption of the ship can increase by up to $85 \%$ in comparison to sailing in calm water [4]. A wave force that acts transversely in the horizontal ship plane and causes the vessel to drift away from its main course is called the drift force [5]. It is not a steady force, but it may include slowly varying components whose frequencies can be close to eigen-frequency [6]. The largest contribution to added resistance and drift loads comes from the incoming waves. However, the ship forward speed also increases the drift loads considerably. A significant deviation of calculated results from the available experimental results and a limited accuracy of added resistance are generally noted when forward speed is present, especially at short wavelengths [7]. This phenomenon may be caused by the hydrodynamic nonlinear effect in the wave diffraction. When the ship forward speed exists, the wave diffraction and nonlinear effects are magnified, so larger differences can be noted between the calculated added resistance and that obtained in experimental results, especially in short waves [8]. The accuracy of the added resistance calculation depends on the accuracy of the ship motion prediction [9]. Numerous methods, based on the linear potential flow theory, boundary elements, and/or the Green function, imply a large number of simplifications. Assuming small wave amplitudes and using the linear theory, it is possible to consider the wave characteristics and the response to waves to be harmonic. In that case, the complicated hydrodynamic problem of interaction between waves and the ship can be solved in the frequency domain [6].

Using the hydrodynamic software HydroSTAR [10], the ship response to regular waves is calculated for different wave headings in a range of wavelength-to-ship length ratios. The purpose of the study is to gain an insight as to how a relatively large free surface of flooded water inside the ship hull influences the motions and added resistance of the ship. Currently available mathematical models and numerical tools are used to enable new insights into sloshing effects of a relatively large free surface. The free surface dimensions express the flooded water surface in several cargo tanks. To distinguish between the influences of the hydrodynamic effect of liquid motions on global ship motions and of the hydrostatic effect, the liquid inside the tank was first treated as a solid body with the sloshing effect excluded. This study is based on the linear potential flow theory and the 3-D panel method. Loads acting on the ship hull are obtained by solving the boundary integral equations while the second-order wave loads can be obtained using three different formulations, i.e. the near-field, the middle-field and the far-field formulation. It is considered that in short waves $(\lambda / L<0.5)$ significant nonlinear effects occur in added resistance calculations. The fact is that incoming short waves mostly reflect in the bow area of the ship, thus causing the main part of the added resistance [2]. Since the results obtained using the method of direct pressure integration along the hull wetted surface are in good agreement with experimental results $[11,12]$, the nearfield formulation is used. The far-field method based on the conservation of momentum is considered to be simpler because there is no need to solve the complete boundary value problem. On the other hand, this method has limitations in treating a proper control surface [2]. Although it is assumed that all methods lead to the same numerical solution in hydrodynamic calculations, in practice it is not the case [13]. The added resistance and drift loads are calculated as the mean values of the second-order wave loading at different frequencies of incoming waves by means of the quadratic transfer function (QTF). Tank in the midship area is partially flooded in order to evaluate the influence of the liquid inside the ship hull on global ship motions and drift loads. Due to the coupling of motions of the ship and the liquid inside the ship tank, significant nonlinearity can occur in a particular frequency range. Despite that, the influence of sloshing is often linearized in the ship motion analysis.

\section{Motion calculations}

In order to calculate the added resistance in waves, an accurate prediction of ship motions is required. The fluid flow around the ship hull is often simulated using the linear 
potential flow theory. This theory gives results with a satisfactory suitability when boundary conditions are carefully defined and fulfilled. Fluid flow is irrotational, incompressible, homogenous and inviscid. The linear potential flow theory is based on the Laplace equation $\Delta \Phi=0$. Knowing the flow velocity potential $\Phi(x, y, z, t)=\operatorname{Re}\left(\varphi(x, y, z) e^{i \omega t}\right)$, the velocity and acceleration of fluid particles the hydrostatic and the hydrodynamic pressure at a given depth can be obtained. The fluid velocity is represented by the gradient of the velocity potential $\Phi$ satisfying the Laplace equation in the fluid domain. The potential should fulfil the following boundary conditions [14]:

$$
\begin{aligned}
& -k \varphi+\frac{\partial \varphi}{\partial z}=0 \text { on } z=0 \\
& \frac{\partial \varphi}{\partial n}=v_{n} \text { on the wetted surface }
\end{aligned}
$$

where $k$ is the wave number, $n$ is the unit surface normal of boundary element, and $v_{n}$ is the collocation point velocity.

The boundary condition on the radiation waves is formulated with respect to the Sommerfeld condition [15]:

$$
\lim _{R \rightarrow \infty}\left[\sqrt{R}\left(\frac{\partial \varphi}{\partial R}-i k \varphi\right)\right]=0
$$

In this paper, all calculations are done using the linear potential flow theory in the frequency domain based on the Laplace equation and satisfying the necessary boundary conditions. The panel method using boundary integral equations is used assuming that there is a small forward speed of the ship. The considered range of $\lambda / L$ is 0.3-2.0. Experimental results that are available for the S-175 container ship are used for the calculation and comparison purposes.

In order to compare the results obtained using the hydrodynamic software HydroSTAR with the available experimental results from the literature, an S-175 container ship hull model and data were used for the calculations of motions and added resistance. The software used for the calculations is based on the linear potential flow theory; it enables the determination of the first and second order motions and loads in a frequency domain based on the hull panels and input parameters of wave characteristics. The software uses the panel method based on boundary integral equations when calculating the seakeeping and sloshing and provides the determination of the diffraction and radiation potentials. The size and shape of distributed panels affect the accuracy of calculations. The panels should be concentrated in the areas where the ship shape changes significantly [16]. The panel method is based on a form of the Green theorem where the velocity potential of the fluid at any point is represented by the surface distribution of singularities over the boundary surfaces [17]. Thus, integral equations should be solved for the strength of unknown sources. If the potential is represented by a source (of unknown strength), the formulation is called the "source formulation". The surface of the body is approximated by a large number of small quadrilateral panels and the source strength/dipole moment is considered to be constant on each panel. The pressure determined from the potential on each panel is integrated in order to obtain required forces and moments. To simulate the energy dissipation that normally occurs due to viscous damping of ship motions and to eliminate extreme responses at resonant frequencies, a fictitious force is introduced in the momentum equations. The ship forward speed is taken into account by the encounter frequency approximation that is implemented in the software HydroSTAR based on 
the Green function that represents the field velocity potential at the field point $P(x, y, z)$ created by a source of unit density located at the singular point $Q\left(x^{\prime}, y^{\prime}, z^{\prime}\right)$ :

$$
4 \pi \Phi(P)=\iint_{H} \mathrm{~d} S\left(\Phi_{n} G-\Phi G_{n}\right)+I_{F}(\Phi)
$$

where $H$ represents the ship hull and $I_{F}$ the free surface integral.

It is possible to transform the free surface integral into a line integral for the wave radiation and diffraction around a ship that moves at a uniform speed. On the other hand, the free surface integral equals zero in most cases when the forward speed is not present [18]. The free surface Green function is usually represented by the sum of one or more Rankine singularities and a component that includes a weakly-singular logarithmic term which is added to satisfy the free surface boundary condition. The Green function satisfies the boundary conditions of the free surface, the bottom and the radiation waves. Therefore, the source distribution should satisfy the body boundary condition and the strength of unknown sources should be obtained to evaluate the forces and moments acting on the ship [13].

The translating-pulsating source method based on the Green function is used in hydrodynamic calculations for cases where forward speed is simulated. Since the method is very time consuming and numerically demanding, when the forward speed is small in amplitude, an approximate free surface boundary condition can be used:

$$
-\omega_{e} \varphi+g \frac{\partial \varphi}{\partial z}=0 \quad \text { on } \quad z=0
$$

Since the low to moderate ship speeds corresponding to $F n<0.3$ are considered in this paper, it was possible to base the calculations on the approximated boundary condition given by equation (5).

\section{Added resistance and drift forces in waves}

When sailing in waves, a ship generates waves associated with the forward speed through still water and waves due to vertical relative motion response to waves [19]. Due to increasing resistance, the forward speed decreases. The ship total resistance in regular waves consists of the resistance in still water (constant at a given speed) and the oscillating resistance due to motions of the ship depending on the encounter frequency. The time averaged part of the resistance increase due to motions related to waves is called the ship added resistance.

In this paper, the ship added resistance is calculated by the direct pressure integration along the hull wetted surface area using the near-field formulation implemented in the software HydroSTAR. The near-field formulation requires the evaluation of the first-order wave field around the hull and along the waterline, as well as the first-order motions caused by that field. The ship local coordinate system is in translatory motion due to hull motions, but also rotates with the angle of rotational motions. Due to the relative motion and variation of the wetted surface area, the integrated vertical hydrodynamic load causes the second order contribution to the mean added resistance [19]. In the method of pressure integration, contributions include the mean component of pressure from the time average of the fluid velocity square and the products of the first-order pressure with oscillatory variations of the hull surface due to motions.

The hydrodynamic load due to incoming waves and the second-order interaction between motion and the wave field of the first-order cause drift loads on the ship hull. The second-order wave loads are composed of sum-frequency loads, i.e. the sum of the first-order 
wave frequencies, and difference-frequency loads, i.e. the low frequency load that oscillates at the frequency equal to the difference between the first-order wave frequencies, $\Delta \omega=\omega_{i}-\omega_{j}$. The low frequency loads include the constant part that is called the drift load [18]. The drift load and the added resistance as a component of the total drift load in the direction of the ship longitudinal axis can be described by the quadratic transfer function (QTF) of incoming waves and diffraction and radiation wave fields. It is therefore necessary to solve the problem of the second-order wave loads. Low frequency second-order wave loads occur at frequencies equal to the difference between two wave frequencies in all possible sea states. They are proportional to the wave amplitude products (QTF) and consist of two parts: the first one depending on the square products of the first-order wave field $F_{q}\left(\omega_{i}, \omega_{j}\right)$ and the second consisting of the second-order wave diffraction potentials and incoming waves $F_{p}\left(\omega_{i}, \omega_{j}\right)$. Second-order low frequency wave loads can be determined by the second-order pressure integration on the hull wetted surface of the ship mean position and by the variation of the first-order loads due to the first-order motions, based on the Froude-Krylov force of the second order and the Haskind integral on the body surface as follows:

$$
F\left(\omega_{i}, \omega_{j}\right)=F_{q}\left(\omega_{i}, \omega_{j}\right)+F_{p}\left(\omega_{i}, \omega_{j}\right)
$$

The first part can be determined by the wave diffraction and radiation solution of the first order while the second part of the second-order wave loads slowly converges and includes gradients of velocity potential [20]. The Haskind integral allows the elimination of the unknown diffraction potential by replacing it with the radiation potential [14]:

$$
\iint_{S} \varphi_{7} \frac{\partial \varphi_{k}}{\partial n} \mathrm{~d} S=-\iint_{S} \varphi_{k} \frac{\partial \varphi_{0}}{\partial n} \mathrm{~d} S, k=1 \ldots 6
$$

where $\varphi_{7}$ is the diffraction potential, $\varphi_{k}$ is the radiation potential, $\varphi_{0}$ is the incoming wave potential, and $S_{0}$ is the wetted surface. QTF is developed as a Taylor series expansion as follows:

$$
F\left(\omega_{i}, \omega_{j}\right)=F_{0}\left(\omega_{i}\right)+F_{1}\left(\omega_{i}\right) \Delta \omega+F_{2}\left(\omega_{i}\right)(\Delta \omega)^{2} / 2+\ldots
$$

The zeroth-order term $F_{0}\left(\omega_{i}\right)$ represents the load due to the integration of the pressure along the hull wetted surface, i.e. the drift force. It depends on the incoming wave frequency as the mean value of two frequencies, $\left(\omega_{1}+\omega_{2}\right) / 2$. The first-order term is linearly proportional to the difference between two frequencies, $\omega_{1}-\omega_{2}$, and the second-order term is proportional to the square of difference between the two frequencies.

The term $F_{1}\left(\omega_{i}\right)$ is composed of four parts:

$$
F_{1}\left(\omega_{i}\right)=F_{q}^{1}+F_{p 1}^{1}+F_{p 2}^{1}+F_{p 3}^{1}
$$

where $F_{q}^{1}$ is the contribution of the first-order wave load, $F_{p 1}^{1}$ is the contribution of the second-order incoming wave load and diffraction waves, $F_{p 2}^{1}$ is the second-order correction of the boundary condition on the hull, and $F_{p 3}^{1}$ is the effect of forcing pressure over the free surface (second-order correction of the boundary condition on the free surface). 
The term $F_{2}\left(\omega_{i}\right)$ does not have an analytical expression but it can be defined as the difference between the total QTF of the bichromatic wave field and the zeroth and the firstorder term mentioned previously:

$$
F_{2}\left(\omega_{i}\right)=\frac{2\left[F\left(\omega_{i}+\frac{\Delta \omega}{2}, \omega_{i}-\frac{\Delta \omega}{2}\right)-F_{0}\left(\omega_{i}\right)-F_{1}\left(\omega_{i}\right) \Delta \omega\right]}{(\Delta \omega)^{2}}
$$

In a particular case of $\omega_{i}=\omega_{j}$, the low frequency wave loads are reduced to constant drift loads that are contributed only by the first part of $F\left(\omega_{i}-\omega_{j}\right)$. The QTF then has a constant value at a given incoming wave frequency.

\section{Influence of sloshing on ship motions and loads}

Seakeeping characteristics of a ship with liquid inside the tank are based on coupled motions of the ship as a rigid body and liquid motions inside the tank. Despite the high nonlinearity of liquid motions inside the closed ship tanks, it is assumed that the most marked influence of sloshing on global ship motions is linear as long as the liquid motions inside the tank are not violent outside the range of resonant frequencies [18]. In that case, a solution in the frequency domain and the linear theory can be used. Also, at low wave frequencies only the hydrostatic effect of the liquid inside the tank is considered to be important. This effect can be taken into account by introducing negative values for the non-zero terms in the stiffness matrix. At low frequencies, the contribution of the liquid inside the tank is nearly like a solid body.

Sloshing and seakeeping analyses are considered separately. When solving the seakeeping problem, the internal tank liquid is considered as a solid body [21]. Motions and loads of the liquid inside the tank are described in the local coordinate system. After calculations, the obtained results are transferred to the global coordinate system of the ship. The boundary integral equation method based on the source formulation is used for both seakeeping and sloshing. The main differences between seakeeping and sloshing are the lack of the diffraction potential inside the tank and a modified free surface boundary condition in the latter [22]. The free surface inside the tank is always horizontal according to the linear theory; thus, a correction of the vertical coordinates is required in the pressure integration along the wetted surface of the tank walls, as shown in Figure 1.

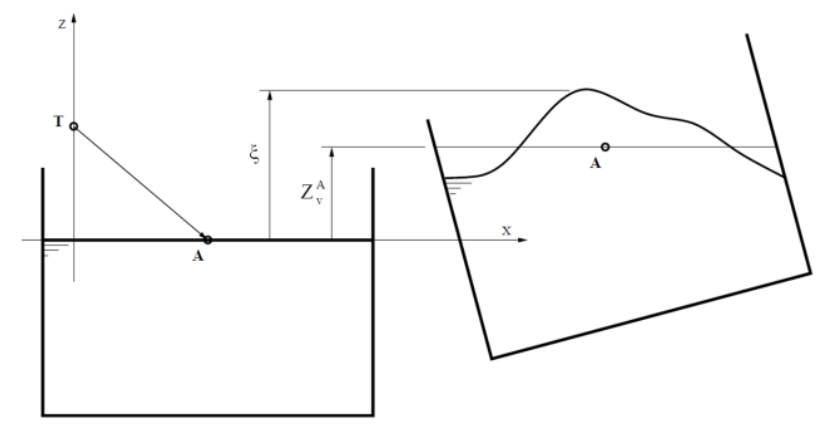

Fig. 1 Motion of the free surface inside the tank [22] 
Dynamic and kinematic boundary conditions inside the tank are expressed as follows:

$$
\begin{aligned}
& \frac{\partial \xi}{\partial t}=\frac{\partial \Phi}{\partial z} \\
& -\rho g\left(\xi-Z_{v}^{A}\right)-\rho \frac{\partial \Phi}{\partial t}=0
\end{aligned}
$$

where $\xi$ is the free surface elevation described with regard to the initial calm condition, $\rho$ is the fluid density, $g$ is the gravity acceleration, and $Z_{v}^{A}$ is the vertical displacement of the of the water plane area centre.

When the linear potential flow theory is used in an analysis of sloshing, there is no damping inside the tank. When the wave frequency approaches the resonant frequency, if no damping is present, the inertia value increases rapidly without a limit. The introduction of the damping factor reduces the value of added inertia, i.e. it creates the energy dissipation in the boundaries of the tank.

\section{Results and discussion}

The results of ship motions and drift loads (moments) obtained using the hydrodynamic software are compared with the available experimental data for the S-175 container ship. A panel model generated using the hydrodynamic software is shown in Figure 2. A mesh of the ship hull has 1346 flat panels up to the waterline. Coordinates and panels of the midship tank are defined in the same way as for the hull mesh. The normal vectors of the panels, used to describe the tank, are directed towards the liquid inside the tank. A mesh of the ship with an internal tank contains 2481 panels. Hydrostatic properties and natural frequencies of the S175 container ship with and without flooded tank are shown in Table 1.

Table 1 Hydrostatic properties and natural frequencies of the S-175 ship with and without flooded tank

\begin{tabular}{lccc} 
& Original ship & $\begin{array}{c}\text { Ship with increased } \\
\text { displacement mass }\end{array}$ & $\begin{array}{c}\text { Ship with } \\
\text { flooded tank }\end{array}$ \\
\hline \hline$T_{F}(\mathrm{~m})$ & 7.0 & 10.5 & 10.5 \\
\hline$T(\mathrm{~m})$ & 9.50 & 13 & 13 \\
\hline$T_{A}(\mathrm{~m})$ & 12.02 & 15.5 & 15.5 \\
\hline$\nabla\left(\mathrm{m}^{3}\right)$ & 24154.13 & 36705 & 36705 \\
\hline$A_{W L}\left(\mathrm{~m}^{2}\right)$ & 3280.7 & 3603.6 & 3603.6 \\
\hline$B M_{x x}(\mathrm{~m})$ & 5.42 & 4.34 & 4.34 \\
\hline$B M_{y y}(\mathrm{~m})$ & 224.63 & 185.85 & 185.85 \\
\hline Heave natural frequency $(\mathrm{rad} / \mathrm{s})$ & 0.840 & 0.764 & 0.764 \\
\hline Roll natural frequency $(\mathrm{rad} / \mathrm{s})$ & 0.847 & 0.506 & 0.905 \\
\hline Pitch natural frequency $(\mathrm{rad} / \mathrm{s})$ & 0.892 & 0.937 & 0.939 \\
\hline
\end{tabular}




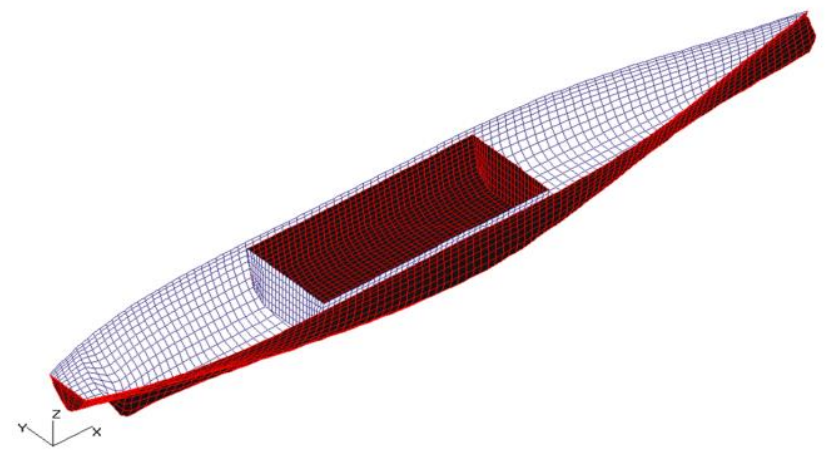

Fig. 2 Panel model of the S-175 container ship with internal tank

\subsection{Transfer functions of the S-175 container ship}

Four Froude numbers are considered $(F n=0 ; 0.15 ; 0.25 ; 0.275)$ at regular waves in the range $\lambda / L=0.3-2.0$. The considered incoming wave headings are $120^{\circ}, 150^{\circ}$ and $180^{\circ}$. Transfer functions of the ship with and without flooded midship tank [21] are calculated. The hydrostatic effect of the flooded tank was obtained by considering the liquid inside the tank as the rigid part of the ship, i.e. the increased displacement mass of the ship. The hydrodynamic effect is determined by coupling the liquid motions in the tank and global ship motions in regular waves [21]. The tank length is $54.75 \mathrm{~m}$ and the maximum width is $22.0 \mathrm{~m}$. The draught of the ship with flooded tank equals $15.5 \mathrm{~m}$ and its displacement volume is 36705 $\mathrm{m}^{3}$.

The two Froude numbers and corresponding speeds, $F n=0.25(v=10.36 \mathrm{~m} / \mathrm{s})$ and $F n=0.275(v=11.39 \mathrm{~m} / \mathrm{s})$, used to compare the transfer functions of the original S-175 ship with those in experimental results are selected because of their availability. For the same Froude numbers, two conditions of the ship with flooded tank are also presented. Transfer functions at the other two Froude numbers follow the same trend as the ones presented here. All experimental data refer to the original ship [23, 24]. The obtained results are shown in Figures 3-9.

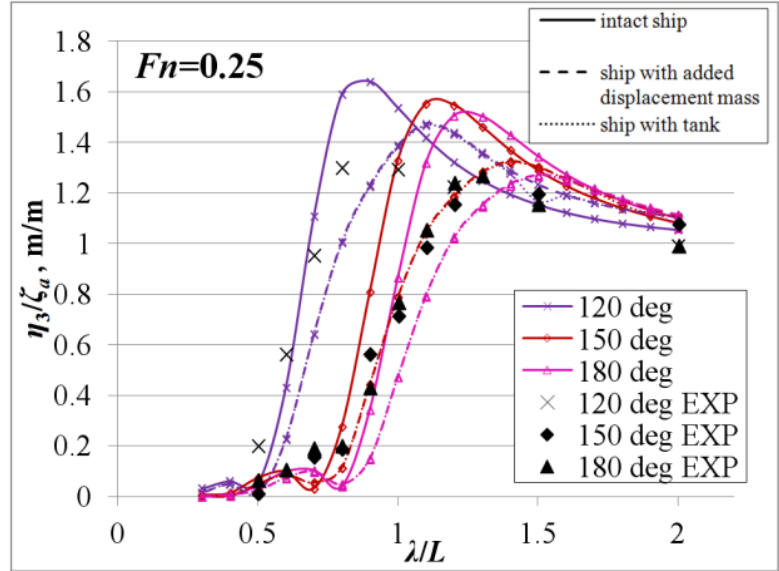

Fig. 3 Comparison of heave transfer functions for $F n=0.25$ and $\beta=120^{\circ} \div 180^{\circ}$

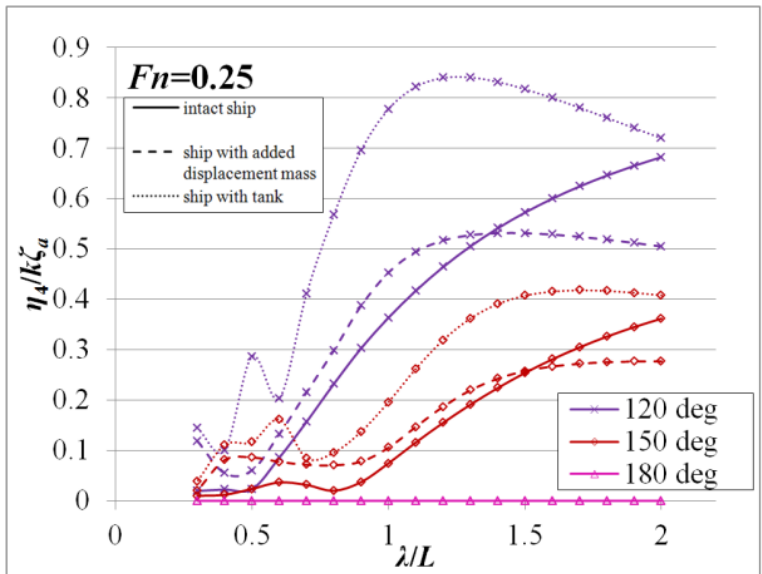

Fig. 4 Comparison of roll transfer functions for $F n=0.25$ and $\beta=120^{\circ} \div 180^{\circ}$ 


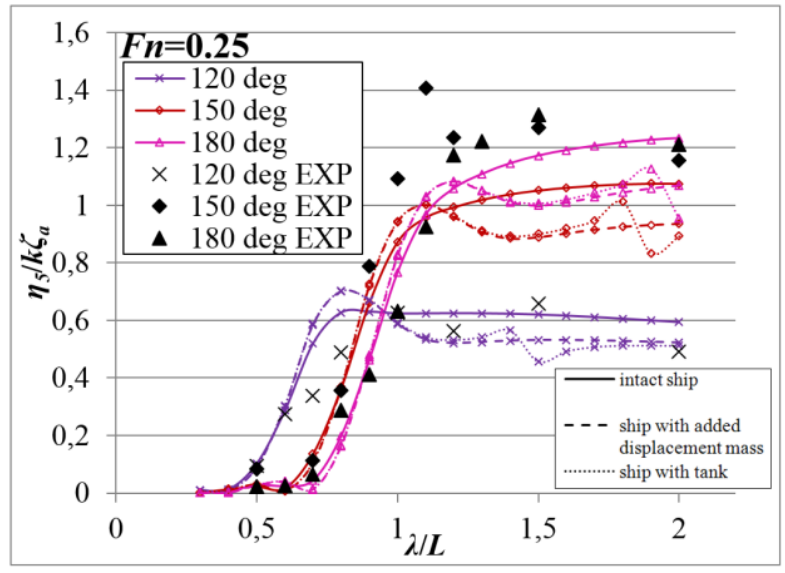

Fig. 5 Comparison of pitch transfer functions for $F n=0.25$ and $\beta=120^{\circ} \div 180^{\circ}$

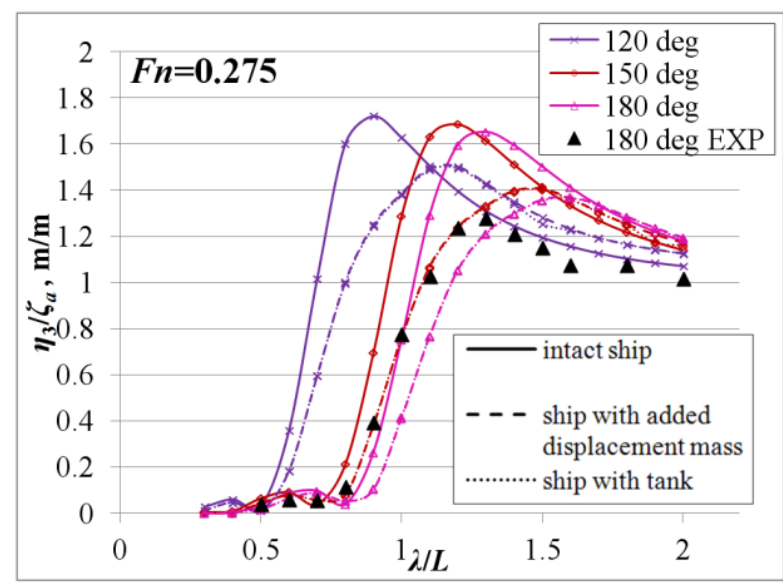

Fig. 7 Comparison of heave transfer functions for $F n=0.275$ and $\beta=120^{\circ} \div 180^{\circ}$

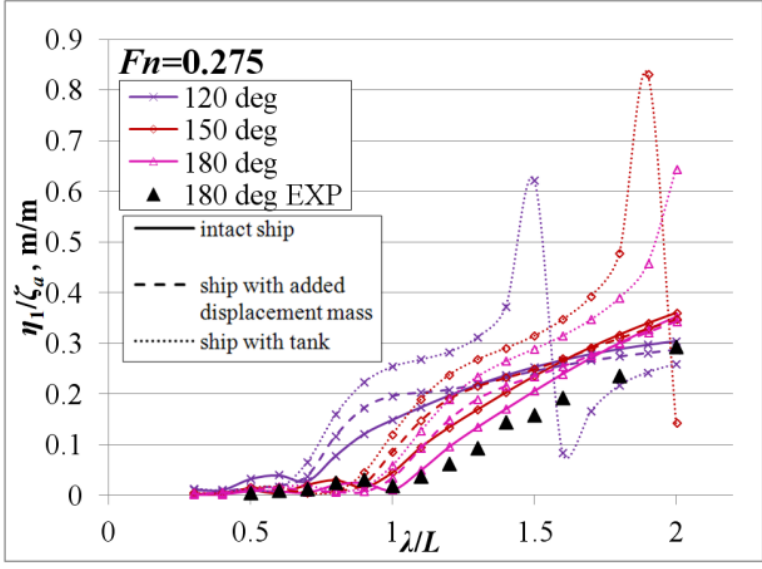

Fig. 6 Comparison of surge transfer function for $F n=0.275$ and $\beta=120^{\circ} \div 180^{\circ}$

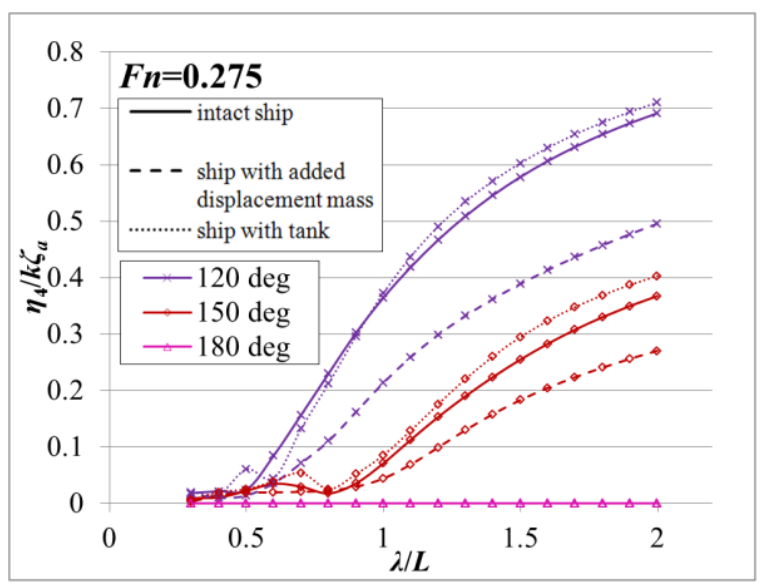

Fig. 8 Comparison of roll transfer functions for $F n=0.275$ and $\beta=120^{\circ} \div 180^{\circ}$

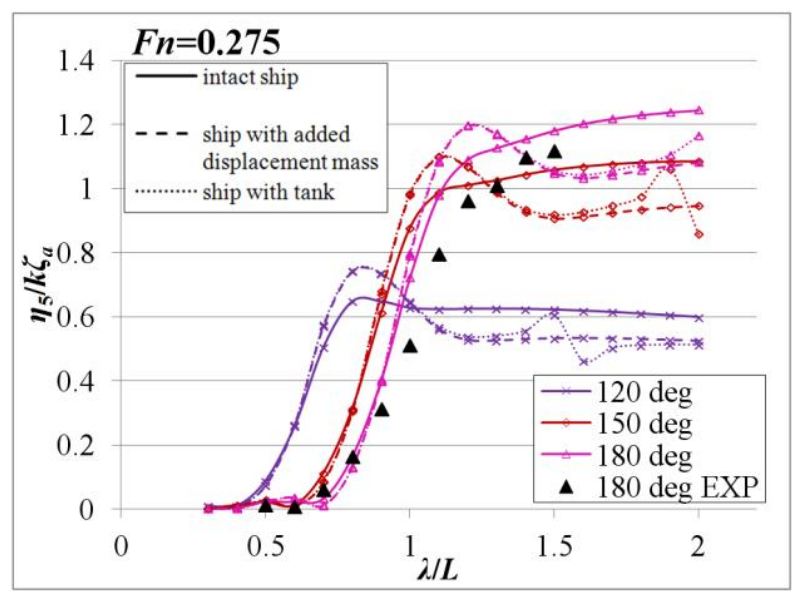

Fig. 9 Comparison of pitch transfer functions for $F n=0.275$ and $\beta=120^{\circ} \div 180^{\circ}$

In the case of heave motions at $F n=0.25$, peaks of the transfer functions of ship with flooded tank are slightly shifted towards lower frequencies. The difference between the transfer functions of the ship with increased displacement mass and the one with flooded water is negligible. The differences between the responses at resonant frequencies of the original ship and the one with the flooded tank in the two conditions are $10 \%$ for the $120^{\circ}$ 
heading, $15 \%$ for the $150^{\circ}$ heading, and $16 \%$ for the $180^{\circ}$. In comparison with the experimental results from the literature, the calculated results overestimate the heave response. The differences between the curves showing the calculated data and those showing the experimental data in the area of resonant frequencies are as follows: $18 \%\left(120^{\circ}\right) ; 23 \%$ $\left(150^{\circ}\right) ; 16 \%\left(180^{\circ}\right)$. The hydrodynamic effect of the liquid inside the tank can be noticed in the case of pitch transfer functions at lower frequencies (higher value of $\lambda / L$ ratio) for the bow and head waves.

The mean differences between the curves showing the pitch response of the original ship and those showing the pitch response of the ship with flooded tank in the two conditions are as follows: $12.3 \%\left(120^{\circ}\right) ; 15.7 \%\left(150^{\circ}\right) ; 19.6 \%\left(180^{\circ}\right)$. The differences between the curves showing the calculated data and those showing the experimental data in the area of resonant frequencies are $5 \%$ for the $120^{\circ}$ heading and $31 \%$ for the $150^{\circ}$ heading. However, the trend of the calculated curve for the $120^{\circ}$ heading is different. The best approximation is obtained for the heading of $180^{\circ}$ with a difference between the peak values of $6.3 \%$.

At the Froude number $F n=0.275$, a significant difference between transfer functions of the ship with increased displacement mass and the ship with liquid inside the tank can be seen in the case of surge and pitch at the bow and head waves at lower frequencies. At these frequencies, resonance occurs between the wave frequency $\omega$ and the tank sloshing frequency $f$, depending on the length of the tank in the excitation direction $L_{t}$ and the height of the water level inside the tank $h$, as follows [25]:

$$
f=\frac{1}{2 \pi} \sqrt{\frac{\pi g \tanh \left(\pi \frac{h}{L_{t}}\right)}{L_{t}}}
$$

The differences between the responses at resonant frequencies of the original ship and the ship with a flooded tank in the case of surge are $51.6 \%\left(120^{\circ}\right)$ and $56.6 \%\left(150^{\circ}\right)$. As the heading of incoming waves approaches $180^{\circ}$, the position of the peak shifts to a lower frequency. In the case of the $180^{\circ}$ heading, the mean difference between the obtained data and the experimental data is $27 \%$. However, the calculated curve of surge response follows the trend of experimental data very well.

In the case of heave motions at the Froude number $F n=0.275$, peaks at the resonant response frequencies are again shifted towards lower frequencies. The differences between the responses at resonant frequencies of the original and the ship with flooded tank in the two conditions are $12.8 \%$ for the $120^{\circ}$ heading, $16 \%$ for the $150^{\circ}$ heading, and $17 \%$ for the $180^{\circ}$. In the case of the $180^{\circ}$ heading, the mean difference between the obtained results and the experimental data is $24.7 \%$. Despite the fact that the calculated results follow the trend of experimental data well, the heave response is overestimated and the difference between the peak values is $22.5 \%$.

The mean differences between the curves showing the pitch response at $F n=0.275$ of the original ship and those showing the pitch response of the ship with flooded tank in the two conditions are as follows: $11.8 \%\left(120^{\circ}\right) ; 13.8 \%\left(150^{\circ}\right) ; 19.8 \%\left(180^{\circ}\right)$. The curve obtained for the $180^{\circ}$ heading differs from the experimental data by $21.9 \%$. However, the trend of the calculated curve is again well approximated.

In the case of roll motions, a significant influence of liquid motions can be observed at lower Froude numbers. At $F n=0.25$, the mean differences between the curves showing the response of the original ship and those showing the response of the ship with increased displacement mass are $25.9 \%\left(120^{\circ}\right)$ and $33.6 \%\left(150^{\circ}\right)$. The mean differences between the curves showing the response of the original ship and those showing the response of the ship 
with a flooded tank are $45.5 \%\left(120^{\circ}\right)$ and $52.3 \%\left(150^{\circ}\right)$. Resonant frequencies of the ship with liquid inside the tank are shifted towards higher frequencies. The differences between the responses at resonant frequencies of the ship with a flooded tank and of the original ship are $40 \%$ for the $120^{\circ}$ heading and $27 \%$ for the $180^{\circ}$ heading.

However, roll motions at higher speeds $(F n=0.275)$ are inadequately described with the increased displacement mass approach used in the studied frequency range. Due to reduced natural frequency of the ship with increased displacement mass, the response value to waves in the case of roll is significantly lower than in the other cases. On the other hand, the response values of the ship with a flooded tank are only slightly higher than those of the original ship for both considered headings. Despite the large amount of the flooded water, its centre of gravity is very close to the ship centre of gravity. Thus, the flooded water does not have a significant influence on the mass moment of inertia at that particular Froude number considering the reduced roll motions at higher speeds. The mean differences between the presented data of the original ship and those of the ship with increased displacement mass are $38.2 \%\left(120^{\circ}\right)$ and $31.3 \%\left(150^{\circ}\right)$.

Generally speaking, the differences between the response amplitudes of the ship with flooded tank with increased displacement mass and that with flooded water are noticeable, but not very significant except in the cases of surge at lower frequencies and roll. Since the ship with flooded tank has reduced natural frequency and an enlarged displacement mass, response amplitudes of the ship motions in particular frequency ranges decrease in comparison with the response amplitudes of the original ship. The hydrodynamic effect can be observed with some ship motions at particular headings. As the ship speed increases, the hydrostatic and hydrodynamic effects are more noticeable except in the case of roll.

\subsection{Added resistance of the S-175 container ship}

Main drift loads in the horizontal ship plane are calculated for four Froude numbers $(F n=0 ; 0.15 ; 0.25 ; 0.275)$ at regular waves in the range $\lambda / L=0.3-2.0$. The considered headings of the incoming waves are $120^{\circ}, 150^{\circ}$ and $180^{\circ}$ since matching experimental data are available for those headings. Based on the near-field formulation, results are obtained for drift forces in the longitudinal direction of the hull, i.e. for the added resistance. Since unidirectional waves are imposed on the ship $(\Delta \omega=0)$, the QTF has a constant unique value for each wave frequency and it is approximated only the with zeroth-order term.

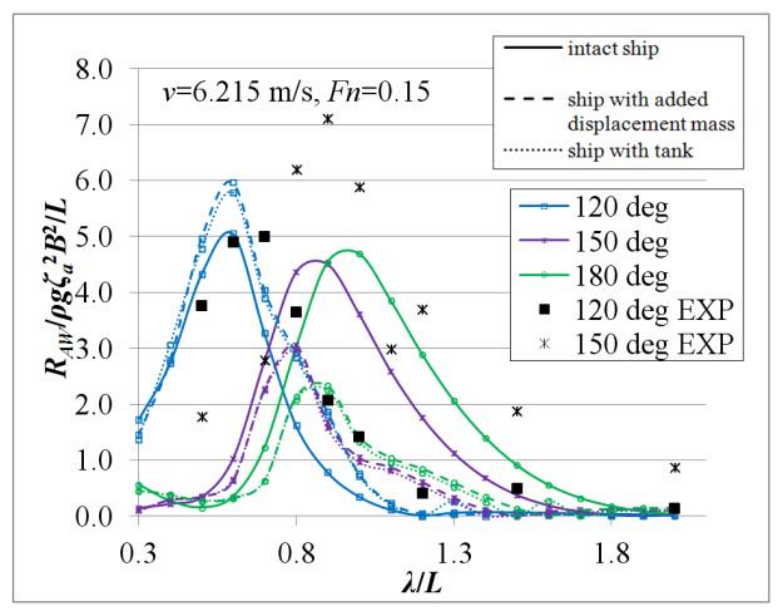

Fig. 10 Comparison of added resistance coefficients for $F n=0.15$

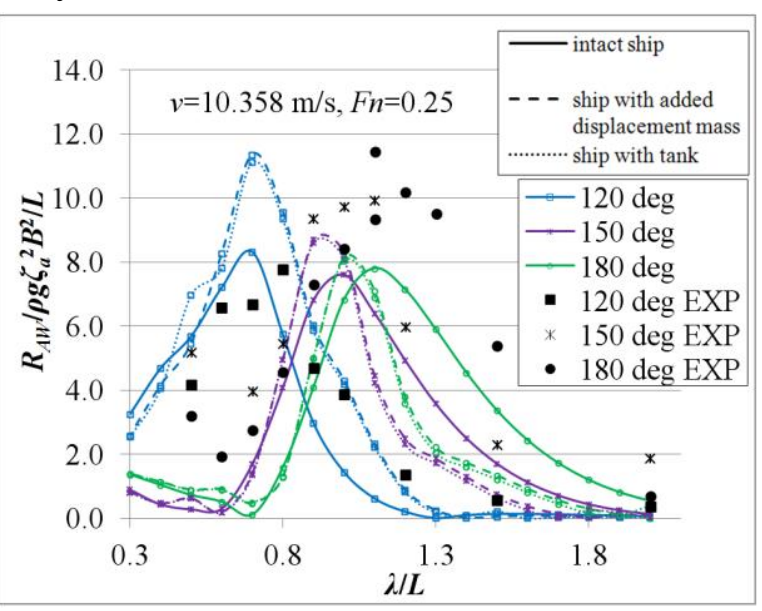

Fig. 11 Comparison of added resistance coefficients for $F n=0.25$ 
The obtained results and the comparison of the dimensionless coefficients of the added resistance are shown in Figures 10 and 11. The experimental results shown in these figures refer to the original ship [26]. $R_{A W}$ refers to the mean added resistance.

The mean differences between the peaks of the curves showing the added resistance coefficients of the original ship and those of the ship with flooded tank in the two conditions at $F n=0.15$ are as follows: $15.3 \%\left(120^{\circ}\right) ; 32.4 \%\left(150^{\circ}\right) ; 50 \%\left(180^{\circ}\right)$. As the heading of incoming waves approaches $180^{\circ}$, the position of the peak shifts to a lower frequency and the differences between the results obtained for the original ship and the ship with flooded tank are larger. However, there is no significant difference between the hydrostatic and the hydrodynamic effect on the ship with a flooded tank. In comparison to the experimental data, the added resistance coefficient curves follow the same trend, but show a significant underestimation of the added resistance in waves in the case of $150^{\circ}$ wave heading. Peaks of the obtained curves are shifted towards higher frequencies. The difference between the calculated peak data and the experimental peak data for the $120^{\circ}$ heading is only $1 \%$, but for the $150^{\circ}$ heading it reaches $36.5 \%$. Since the zeroth-order approximation of the QTF and the second-order wave loads are used, the added resistance is possibly underestimated. The mean differences between the peaks of the original ship and those of the ship with flooded tank in the two conditions at $F n=0.25$ are as follows: $26.7 \%\left(120^{\circ}\right) ; 12.4 \%\left(150^{\circ}\right) ; 4.4 \%\left(180^{\circ}\right)$. Again, an insignificant hydrodynamic effect of flooded water can be observed except in the case of the $120^{\circ}$ heading at high frequencies. The differences between the calculated peak data and the experimental peak data are as follows: $6.7 \%$ for the $120^{\circ}$ heading, $23.5 \%$ for the $150^{\circ}$ heading and $17.9 \%$ for the $180^{\circ}$ heading.

\section{Conclusion}

The linear potential flow theory used in ship motion and wave load calculations shows good results in predicting the ship response to waves and the added resistance. The presented method is used for making a preliminary evaluation of the influence of sloshing on ship motions and loads. Despite the obvious difference between the transfer functions of the original ship and those of the ship with a flooded internal tank, one can conclude that the hydrodynamic effect of the liquid motions is not significant in most cases except for the surge and roll motions. Notable differences between these transfer functions can also be seen in roll motions. The added displacement mass approach inadequately describes (significantly underestimates) the influence of flooded water on global ship motions at higher Froude numbers. Even though sloshing generally has a significant influence on roll, the flooded water in this case does not significantly affect the mass moment of inertia of the ship. On the other hand, at lower speeds, one can observe a significant influence of liquid motions on global roll motions. The added resistance of the ship with flooded tank increases at higher Froude numbers. The same can be observed in the cases of the drift forces and moments. However, the hydrodynamic effect of liquid motions inside the tank is not very significant. The calculated transfer functions obtained for the bow and head incoming waves show good agreement with the experimental data in the case of surge, but can overestimate (heave) or underestimate (pitch) the actual ship response to waves. The calculated added resistance in waves is underestimated with respect to that in the experimental data since it was approximated only with the QTF zeroth-order term. The results obtained at all considered ship speeds show the same trend with an increasing sloshing effect on the ship motions and loads at higher speeds. The determination of the impact that the liquid inside the tank will have on global motions of the ship after collision or grounding can be of great importance in predicting, for example, the towing route. Bearing in mind the simplifications that the linear potential flow theory uses, experimental validation of the obtained results may be beneficial. 
Evaluation of the added resistance and motions of a ship

coupled with sloshing using potential flow theory

\section{REFERENCES}

[1] Prpić-Oršić, J., Faltinsen, O.M.: Estimation of ship speed loss and associated CO2 emissions in a seaway, Ocean Engineering, Vol. 44, No. 1, 2012., pp. 1-10. http://dx.doi.org/10.1016/j.oceaneng.2012.01.028.

[2] Seo, M.G., Park, D.M., Yang, K.K., Kim, Y.: Comparative study on computation of ship added resistance in waves, Ocean Engineering, Vol. 73, 2013., pp. 1-15. http://dx.doi.org/10.1016/j.oceaneng.2013.07.008.

[3] Liu, S., Papanikolaou, A., Zaraphonitis, G.: Prediction of added resistance of ships in waves, Ocean Engineering, Vol. 38, No. 4, 2011., pp. 641-650. http://dx.doi.org/10.1016/j.oceaneng.2010.12.007.

[4] Degiuli, N., Ćatipović, I., Martić, I., Werner, A., Čorić, V.: Influence of added resistance in regular waves on ship fuel consumption, Proceedings of the 9th Conference on Sustainable Development of Energy, Water and Environment, 9th SDEWES Conference, Venice-Istanbul, 2014., pp. 1-12.

[5] Zeraatgar, H., Abed, H. F.: Added resistance \& drift force analysis in regular and irregular waves, Journal of Marine Engineering, Vol. 2, No. 1., 2006.

[6] Prins, H.: Time-Domain Calculations of Drift Forces and Moments, PhD thesis, Delft University of Technology, Netherlands, 1995.

[7] Kashiwagi, M., Ikeda, T., Sasakawa, T.: Effects of Forward Speed of a Ship on Added Resistance in Waves, International Journal of Offshore and Polar Engineering, Vol. 20, No. 3, 2010., pp. 196-203.

[8] Duan, W., Li, C.: Estimate of added resistance for large blunt ship in waves, Journal of Marine Science and Application, Vol. 12, Issue 1, 2013., pp. 1-12. http://dx.doi.org/10.1007/s11804-013-1177-6.

[9] Matulja, D., Sportelli, M., Guedes Soares, C., Prpić-Oršić, J.: Estimation of Added Resistance of a Ship in Regular Waves, Brodogradnja, Volume 62, No. 3, 2011., pp. 259-264.

[10] HYDROSTAR for Experts, v6.11, 2010. Bureau Veritas, Paris.

[11] Martić, I., Degiuli, N., Ćatipović, I.: Added resistance in waves of intact and damaged ship in the Adriatic Sea, Brodogradnja, Volume 66, No. 2, 2015., pp. 1-14.

[12] Nakayama, Y., Yasukawa, H., Hirata, N., Hata, H.: Time Domain Simulation of Wave-induced Motions of a Towed Ship in Head Seas, Proceedings of the Twenty-second (2012) International Offshore and Polar Engineering Conference, Rhodes, Greece, 2012., pp. 901-907.

[13] Guha, A., Falzarano, J.: The effect of hull emergence angle on the near field formulation of added resistance, Ocean Engineering, Vol. 105, 2015., pp. 10-24. http://dx.doi.org/10.1016/j.oceaneng.2015.06.012.

[14] Prpić-Oršić, J., Čorić, V.: Pomorstvenost plovnih objekata, Zigo, Rijeka, Croatia, 2006.

[15] Joncquez, S., Simonsen, C.D., Otzen, J.F.: Computational Evaluation of the Added Resistance in Oblique Seas, Proceedings of the 27th International Workshop on Water Waves and Floating Bodies, 22-25 April 2012., Copenhagen, Denmark.

[16] Seo, M.G., Yang, K.K., Park, D.M., Kim, Y.: Numerical analysis of added resistance on ships in short

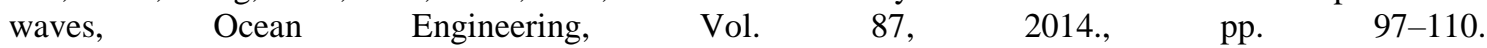
http://dx.doi.org/10.1016/j.oceaneng.2014.05.011.

[17] Lee, C.H., Newman, J.N.: Computation of wave effects using the panel method, Numerical models in fluid-structure interaction, Preprint, Editor S. Chakrabarti, WIT Press, Southampton, 2004.

[18] Chen, X.B.: Hydrodynamics in Offshore and Naval Applications-Part I, Proceedings of the 6th International Conference on Hydrodynamics (ICHD '04), Perth, Australia, 2004.

[19] Journée, J.M.J., Massie W.W.: Offshore Hydromechanics, Delft University of Technology, Delft, Netherlands, 2001.

[20] Chen, X.B., Rezende, F.: Computations of low-frequency wave loading, Proceedings of the 23rd International Workshop on Water Waves and Floating Bodies, 23rd IWWWFB, Jeju, Korea, 2008., pp. 21-24.

[21] Martić, I., Degiuli, N., Ćatipović, I.: Seakeeping characteristics of intact and damaged ship in the Adriatic Sea, Proceedings of 16th IMAM Congress - Towards Green Marine Technology and Transport IMAM, 2015., pp. 159-166. http://dx.doi.org/10.1201/b18855-22.

[22] Malenica, Š., Zalar, M., Chen, X.B.: Dynamic coupling of seakeeping and sloshing, Proceedings of The Thirteenth (2003) International Offshore and Polar Engineering Conference, 13th ISOPE Conference, Honolulu, Hawaii, USA, May 2003., pp. 486-492. 
[23] Takahashi T.: A practical prediction method of added resistance of a ship in waves and the direction of its application to hull form design, Trans West Jpn Soc Nav Archit (1988) 75, 1988., pp. 75-95.

[24] ITTC: Report of the Seakeeping Committee, Proceedings of the 16th International Towing Tank Conference, 1981., pp. 217-224.

[25] Faltinsen, O.M., Timokha, A.N.: Sloshing, Cambridge University Press, Cambridge, England, 2009.

[26] Fujii, H., Takahashi, T.: Experimental Study on the resistance increase of a ship in regular oblique waves, Proceedings of the 14th ITTC, International Towing and Tank Conference, National Research Council of Canada, 1975., pp. 351-359. http://dx.doi.org/10.2534/jjasnaoe1968.1975.132.

Submitted: 15.05.2016. Ivana Martić, ivana.martic@ fsb.hr Nastia Degiuli, Ivan Ćatipović

Accepted: 12.10.2016. University of Zagreb, Faculty of Mechanical Engineering and Naval Architecture, Ivana Lučića 5, 10000 Zagreb, Croatia 